\title{
The Use of Facebook as a Media for Career Guidance and Counseling Services in Junior High School
}

\author{
Abdul Kholiq*, M. Solehuddin \\ Department of Guidance and Counseling, School of Postgraduate \\ Universitas Pendidikan Indonesia \\ Bandung, Indonesia \\ *abdulkholiq@upi.edu, msolehuddin@upi.edu
}

\begin{abstract}
There were many students who did not know their potencies and many others who did not continue to higher education after graduated. These problems were happening until a guidance and counseling teacher used Facebook in her services. She used Facebook to give information and help the students in preparing their career. The Research aimed at investigating the roles of Facebook as a media to provide counseling service and to give useful information on career path for students. The study used qualitative methods with narrative research design. The data were collected through interview. The result of the study, based on success analysis, indicated that guidance and counseling in schools was developing to be more successful as Facebook was involved in providing students' services. The significant results were implied from the increasing percentage of students who graduated from school that recently achieved $100 \%$ and many of them who continue to senior high school. In addition, the Facebook network also helps the alumni to communicate with school counselor who help them to continue their studies to reputable colleges.
\end{abstract}

Keywords: career, Facebook, guidance and counseling, services

\section{INTRODUCTION}

Guidance and counseling is an integral part of education which supports the achievement of the objectives of education. In particular, guidance and counseling aims to help students to develop optimally, independently, and in harmony with their environment. Therefore, the implementation of guidance and counseling through its services and programs is very important in helping students to be successful in academic and nonacademic. Guidance and counseling comprehensively provides preventive function so as not to cause problems and healing function to help students who have obstacles or problems.

According to Yusuf the basic consideration of the application of guidance and counseling programs in schools is the awareness or commitment to facilitate students to develop their potency and achieve their development tasks [1]. Moreover, Yusuf also stated that someone will reach maturity to understand themselves and others, have moral insight, and have the ability to think in an integrated manner, through formal education [1]. Therefore, the role of guidance and counseling is to facilitate students to have effective daily lives.
The implementation of guidance and counseling program at junior high school is connected to the development of adolescents. The program is expected to support the efforts to develop the potential of adolescents optimally and to recognize the achievement of overall education success. This implies that optimal adolescent development will be achieved through the implementation of a good guidance and counseling program that is systematic, structured, and sustainable. There are four areas of guidance and counseling services, namely personal, social, learning, and career. In this study, the career aspect will be discussed regarding the preparation of career choices for junior high school students.

The concept of career services in junior high school students includes specialization of extracurricular activities in the school, selection of science learning activities groups, and making post-graduate decisions to continue their studies or choosing other options. Based on the concept, the final goal of career guidance and counseling services in junior high schools is that the students can determine their life choices after graduation independently. A school counselor or also called a guidance and counseling teacher evaluates the process and the results to assess the provision of guidance and counseling services.

School counselors in their evaluation activities are required to be able to adjust their service content to be updated. In modern era it is known that there are changes in human lifestyles, one of which is in the form of communication that uses many technological devices and in which there is social media. One of the most popular types of social media is Facebook. In the 2019 preliminary study of 113 respondents from various provinces in Indonesia which were randomly selected it was found that $75.2 \%$ of people used Facebook.

In summary, study material has been obtained, namely career guidance services and opportunities for using Facebook social media. Thus, the important point is that whether the school counselor is able to take advantage of the rampant phenomenon of using Facebook as one of the media to carry out guidance and counseling services or not, and then find out the mechanism and its effectiveness. These questions will be examined in this study with the topic of career guidance and counseling services through Facebook. 
students are comfortable to share academic information using Facebook.

On the other hand, Facebook can also be employed as a communication medium for negative purposes by students, namely to do juvenile delinquency [10]. It was also stated that the use of social media, especially Facebook, has negative impact such as students' decreasing learning achievement so that school counselors must provide appropriate counseling services [11]. In addition, school counselors must also be aware that the negative impacts of using social media include several addictions, cyberbullying, and others [12]. Therefore, It is recommended based on his research that school counselors in schools should anticipate the negative impact of social media use for students [13]

School counselors in schools must be able to utilize social media for one of their services effectively in accordance with the rules of professionalism [14]. Counselors can gain student understanding by examining both the content and functions of student self-disclosure through Facebook [15]. In addition, it was explained that Facebook creates a therapeutic place or environment that encourages deep self-disclosure by clients. The information about client's emotions and behavior are important for the therapist or in this context is a teacher of guidance and counseling. Therefore, Facebook can be used as a valuable tool to give counseling intervention which is directly linked to client behavior.

Having known that young people intensively use social media, school counselors need new strategies and resources to connect with young people [16]. The findings underline the importance of considering the relationship between personal attributes, perceptions of media effectiveness, and media behavior in assessing social media applications for users' psychosocial well-being [17]. Hence, the school counselors can use Facebook as one of the popular social media to provide services to students as well as to reduce the negative impact of Facebook use.

In summary, many school counselors nowadays are adapting to the advancement of technology. One of them was using Facebook as one of flagship programs of guidance and counseling service in school. Based on the previous researches, there were no specific research which studied the use of Facebook in career guidance and counseling service. This research could be the one that may enrich the study of career guidance and counseling. Therefore, the result of this research could trigger the further researchers to develop guidance and counseling programs which are related to the advancement of technology.

\section{METHODS}

The study was conducted using qualitative methods, specifically narrative research design. The scheme of the research based on Creswell's theory that consist of several steps such as: research problem identification, literature review, research question development, qualitative data collection, analysis and interpretation of the collected data, and writing the data. The characteristic of this research is the experiences of an educational value when there are strong classmates among students [9]. In addition, it is mentioned that 
individual. The sample of the study was a school counselor in a junior high school who utilized Facebook in career guidance services for students. The data collection technique employed was interview. The instrument's content validity was developed and tested based on the regulation of guidance and counseling implementation in junior and senior high school which is published by the ministry of education and culture of Indonesia number 111 year 2014 [18].

\section{RESULTS AND DISCUSSION}

Based on the results of the interviews with respondent, it is revealed that students were lack of information about further study and employment after graduation. Respondents stated that based on the data from students' needs analysis, students were proven to have inadequate knowledge and career preparation. In the final year of junior high school, the ability to determine life choices is a prior competency to be considered important. Thus, a unit of guidance service activities is prepared according to the students' needs. One component that is a priority to be developed is to recognize the types and characteristics of further studies and work [19].

Career guidance strategies implemented are the basic services and individual planning. Basic services are carried out with several types of services, namely classical guidance, group guidance, collaboration with subject teachers, and student data collection. Classical guidance was carried out in the classroom with material in the form of career information. One form of material provided was service orientation and information about careers. Besides, group guidance on career topics was also carried out and collaboration with subject teachers was integrated in school programs for example in student activities [20]. In addition, school counselors also collected student data comprehensively as one form of service provided called data collection services. Then, individual planning services are carried out with an assessment strategy and some advice either individually or in groups. The concrete activities are in the form of class placements, extracurricular activities distribution and placement, and field trips as a form of career recognition.

In carrying out their duties as a whole, the school counselor did a number of efforts. First, doing "need assessment" related to student characteristics, developmental tasks, problems experienced, motivation to learn, and so on. Second, organizing and managing guidance and counseling programs. Third, providing information about guidance programs to students, teachers, parents, principals, and administrative staff. Fourth, accommodating information to students about various aspects of life that are useful for students. Fifth, preparing group guidance services to students related to personal, social, learning and career aspects. Sixth, setting group counseling services to students related to personal, social, learning and career aspects. Seventh, arranging individual counseling services to students related to personal, social, learning and career aspects [21]. And finally, evaluating the guidance and counseling program that has been carried out.

Evaluation was generally intended to determine the effectiveness of the activities implementation and the achievement of predetermined program objectives. It is also to appraise the services done and know the impact of those services $[22,23]$. The activity was accomplished by examining the guidance and counseling program that has been and is being implemented, the results of which can be the basis for school counselors to develop and improve the next program. In addition, evaluation can be used to provide feedback for the programs in order to improve the implementation of the next program. There are several evaluations done in the study.

First, evaluation of the process, which is carried out during the provision of individual guidance services took place [23]. There are aspects that are evaluated, for instance the activeness of students in activities, student enthusiasm, conformity with applicable procedures, and allocation of time of service delivery in accordance with the predetermined plan. Second, evaluation of results, especially the assessment process after the service is completed [23]. The aspects assessed were students' new understanding, changes in student attitudes, students' feelings, students' beliefs in their abilities, students' motivation to develop their potential, and student activity plans after being given the service.

Based on the results of the evaluation conducted, the service strategy that has been carried out needed to be supported by a service innovation that utilized technological advancements [24]. Guidance services using Facebook was implemented from 2012 to 2017. The school counselor created a Facebook account then made friends with the students. The personal school counselor's account was connected to students and alumni. Guidance services using Facebook later became one of the top programs in the school. The results of the service are explained in table 1.

TABLE I. THE RESUlTS OF CAREER GUIDANCE AND COUNSELING SERVICES

\begin{tabular}{|l|l|l|}
\hline \multicolumn{1}{|c|}{ Indicators } & \multicolumn{1}{c|}{ Before } & \multicolumn{1}{c|}{ After } \\
\hline Insight and career preparation & Low & Middle to high \\
\hline $\begin{array}{l}\text { Number of students who continued to study } \\
\text { Percentage of students who academically } \\
\text { graduated }\end{array}$ & Few & Many $(80 \%)$ \\
\hline Students delinquency & Some cases & Decreased \\
\hline
\end{tabular}

The initiation of using Facebook as one of the guidance services was started since the school did not allow school counselor to have regular class with students. Consequently, school counselors took the initiative to take advantage of technological advances such as Facebook social media. Guidance and counseling services used Facebook since it was first created until 2017. Almost every day, the school counselor distributes motivational advice, uploads photos of school activities related to achievements to appreciate students so they can broaden their insights on the importance of continuing school to achieve success. It is known that students are interested in using Facebook because teachers become more open to communicating with students $[19,24]$.

Another positive thing from this service using Facebook is that school counselor can monitor the development of students' behavior outside the school [25]. The statuses of students can 
reveal some things about their circumstances or feelings that might have something to do with their condition in school. This was collected by the school counselor and made as a data set that was taken into consideration in providing services. After the school emerged that guidance and counseling in schools had time to provide classical services, guidance and counseling services using Facebook continued until the end of 2017 when the teacher moved to teaching assignments in other schools.

Through counseling and counseling services through Facebook, counseling and guidance teachers can provide services not only during study hours but also at any time [26]. As long as the teacher and students interact on social media, the relationship can be closer because the teacher can make friend to students. An advantage is that it is easier to discover things that need to be known. Through Facebook, students are more convenient to open themselves in expressing things that are privacy to the teacher. Thus, guidance and counseling services using Facebook is one form of service provided by the teacher of guidance and counseling at school.

In 2015, an evaluation was carried out and information was obtained that there was a significant development about order and students' learning success. From the attendance recap, it can be seen that most grades for student attendance were good which indicated that students were active in going to school. In addition, the percentage of students to graduate on time was increasing, which raised to $100 \%$. Furthermore, it is strengthened by the reduced number of cases in student delinquency. According to respondents, the most visible success was when there were four students who could continue their education to senior high school. The number of students who graduated in 2015 and those who went on to school reached $80-90 \%$ which increased from previous years. While more alumni could continue to higher education and even applied to reputable universities.

The changes explained above were caused by Facebook's superiority that can connect alumni with teachers so that the guidance process can be continued. Through Facebook, both students and alumni can discuss and exchange information [20, 21]. The Facebook school counselor's account is still active and there are daily interactions within it. At least 1500 students and alumni were connected. They are still communicating even among alumni who are still consulting about their lives now even though they are no longer junior high school students.

From the explanation above, it can be concluded that the indicators of success are seen in students who have the knowledge and understanding of themselves according to what they need. Students experience attitude changes and can modify or make behavioral changes. They believe in their potential and are motivated to develop their potential optimally. In addition, they have various alternative solutions to the problems they face and have planned activities to be carried out in the future.

\section{CONCLUSION}

The guidance and counseling program is structured systematically and is oriented towards a comprehensive approach aimed at achieving the development tasks of potential students. School counselors can use facilities that develop along with technological developments, one of which is using Facebook. The service extends the workspace of school counselors and can connect between teachers and students and alumni continuously.

Based on the indicators of success analyzed, guidance and counseling career services in schools developed to be more successful affected by the involvement of services using Facebook. By using Facebook as one of flagship program in school, the guidance and counseling teacher obtained several achievements. The students' insight and career preparation were increased significantly. The number of the students who continued to study was increased too as the percentage of students who academically graduated became $100 \%$. The number of student's delinquency was also affected to be decreased as classified as good impact of the service.

In sum, the service accommodates the needs of the era from time to time and can be recommended to other school counselors because these developments will continue to occur. Thus, it is recommended for the next researcher to study about the use of another advanced technology as media of guidance and counseling service.

\section{ACKNOWLEDGMENT}

The authors would like to thank to the teacher of guidance and counseling of SMPN 1 Cilengkrang Bandung, Indonesia.

\section{REFERENCES}

[1] S. L. N. Yusuf, "Program bimbingan dan konseling di sekolah", Bandung: Rizqi Press, 2009.

[2] I. T., Awidi, M. Paynter, and T. Vujosevic, "Facebook group in the learning design of a higher education course: an analysis of factors influencing positive learning experience for students", Computers \& Education, vol.129, pp. 106-121, 2019. doi: 10.1016/j.compedu.2018.10.018

[3] S. Cicevic, A. Samcovic, and M. Nesic, "Exploring college students' generational differences in Facebook usage", Computers in Human Behavior, vol. 56, pp. 83-92, 2016. doi: 10.1016/j.chb.2015.11.034

[4] A. Alarabiat, and S. Al-Mohammad, "The potential for Facebook application in undergraduate learning: a study of Jordanian students", Interdisciplinary Journal of Information, Knowledge, and Management, vol. 10, pp. 81-103, 2015.

[5] P. Amador, and J. Amador, "Academic advising via facebook: examining student help seeking", Internet and higher education, vol. 21, pp. 9-16, 2014. doi: 10.1016/j.iheduc.2013.10.003

[6] N. B. Hamutoglu, M. Kiyici, and A. Isman, "Facebook literacy in education", Procedia-Social and Behavioral Sciences, vol. 106, pp. 1218- 1221, 2013. doi: 10.1016/j.sbspro.2013.12.136

[7] Q. Wang, H. L. Woo, C. L. Quek, Y. Yang, and M. Liu, "Using the Facebook group as a learning management system: an exploratory study", British Journal of Educational Technology, vol. 43, pp. 428-438, 2012.

[8] K. Moorthy, L. C. T'ing, K. M. Wei, P. T. Zi Mei, C. Y. Yee, K. L. Jia Wern, and Y. M. Xin, "Is Facebook useful for learning? A study in private universities in Malaysia", Computers \& Education, 2019. doi: 10.1016/j.compedu.2018.12.002 
usefulness, and use patterns", Computers in Human Behavior, vol. 46, pp. 245-253, 2015. doi: 10.1016/j.chb.2015.01.015

[18] Ministry of education and culture of Indonesia number 111 year 2014 about the implementation of guidance and counseling in junior and senior high school.

[19] C. Rojas-Kramer, I. Esquivel-Gamez, and A. García-Santillan, "Educational use of Facebook in higher-education environments: current practices and guidelines", 2015.

[20] D. Lambic, "Correlation between Facebook use for educational purposes and academic performance of students", Computers in Human Behavior, vol. 61, pp. 313-320, 2016. doi: 10.1016/j.chb.2016.03.052

[21] M. Dindar, and Y. Akbulut, "Why do pre-service teachers quit Facebook? An investigation on 'quitters forever' and 'quitters for a while", Computers in Human Behavior, vol. 39, pp. 170-176, 2014. doi: 10.1016/j.chb.2014.07.007

[22] J. W. Creswell, "Educational Research: Planning, Conducting, and Evaluating Quantitative and Qualitative Research, fourth edition", Boston: Pearson Education, 2012.

[23] Sugiyo, and Muslikah, "Evaluation Models of Guidance and Counseling Service Based CIPP in Senior High School", Advances in Social Science, Education and Humanities Research, vol. 249, pp. 242-249.

[24] C. T. Anni, Sunawan, and Haryono, "School Counselors' Intention to Use Technology: The Technology Acceptance Model", TOJET: The Turkish Online Journal of Educational Technology, vol. 17 (2), pp. 120124.

[25] P. R. Mullen, C. Griffith, J. H. Greene, and G. W. Lambie., "Social Media and Professional School Counselors: Ethical and Legal Considerations", University of Central Florida, [online]. Retrieved from https://files.eric.ed.gov/fulltext/EJ1034737.pdf

[26] J. G. Froeschle, C. R. Crews, and J. Li. "Ethically Assisting Students Via Social Media", VISTAS articles, Alexandria:American Counseling Association, 2013. 